\title{
Study on the Biomass Energy and Its Industrial Development
}

\author{
Siyi Zhang \\ Hainan University, Haikou, Hainan, 570228
}

Keywords: Biomass Energy, Industrial Development, Energy Reserve

\begin{abstract}
In recent years, due to the shortage of energy sources such as oil and natural gas, their prices have risen sharply. At the same time, the environmental problems caused by the traditional energy utilization have become increasingly prominent. Therefore, the development of agricultural biomass and its related industries, as an effective alternative to fossil fuels, is of great significance for optimizing energy structure, reducing dependence on foreign countries, ensuring national energy security and stabilizing energy supply system.
\end{abstract}

\section{Introduction}

At present, the biomass energy industry innovation model and industrial chain are gradually forming in the renewable energy field, and the long-term economic boom based on the biomass energy industry innovation model is gaining momentum. Many countries have formulated or are planning to develop their own biomass energy development plan. The general objective is to replace $10 \%$ to $30 \%$ of the energy from biomass by $2030-2050$ [1]. It can be predicted that with the increase of biomass energy Industrial technology to non-food biomass innovation and transformation, biomass energy industry model will become Chinese strategic alternative to fossil fuels to ensure energy security and the peaceful rise of the clean energy foundation for the country's economic development to provide agricultural and rural areas with Chinese characteristics. In the context of the development of new energy sources, what the energy reserves require for the development of biomass energy industry in China? What are the characteristics of its distribution and energy density? What are agricultural biomass energy utilization technologies? If the use of technology has reached industrialization, how about the status quo of its industrial development, its market structure, and its market behavior? What are the bottlenecks in the development of biomass energy industry, how to solve it? Biomass energy industry should follow what kind of development model? This study will elaborate on these issues.

\section{Analysis of the Current Situation of Agricultural Biomass Energy Industry in China}

Biomass energy technologies used in Chinese biomass energy sources include crop straws, forest waste, rubbish and biogas. Among them, biomass direct fired power generation, mixed generation (mixed combustion of biomass and coal), biogas power generation, gasification power generation is currently more mature domestic control. Among them, direct-fired power generation is Chinese most widely used biomass power generation technology. As of 2010, Chinese biomass power generation project has been in operation and production phase of 81 , while direct fired power station stood $80 \%$. According to statistics, as of the beginning of 2011, the total installed capacity of biomass power generation increased by $14 \%$, second only to the EU, the United States and Germany[2].

The biomass power generation structure is roughly as follows: The total installed capacity of straw direct combustion for power generation accounts for $62 \%$ of the total installed capacity of biomass power generation, reaching 3.41 billion; followed by waste incineration, accounting for $29 \%$ of the total biomass power generation, To 1.59 million kilowatts [33]. Other forms of power generation accounted for about $9 \%$. In addition, as we all know, the biggest benefit of biomass compared with traditional coal plants lies in the low emission of pollutants. According to statistics, a 25 GW biomass power plant can be reduced by 100,000 compared with similar coal-fired power 
plants Tons of carbon dioxide emissions [3]. However, in the overall planning of the biomass power generation industry, we also have to consider the emission of pollutants to the environment during the direct-fired power generation.

For the current domestic biomass power generation projects, there are many specific technologies for generating electricity, mainly including straw direct combustion power generation, gasification combustion power generation, agricultural and forestry waste mixed combustion power generation, gasification co-combustion power generation, waste incineration power generation, landfill gas and biogas Direct combustion power generation, different technologies have different characteristics, of which, agricultural and forestry waste mixed-burning power generation is still in its infancy, how to transform the existing coal-fired power plants to adapt to the technology of biomass fuel remains unresolved, landfill gas and biogas Direct fired power generation has the advantages of simple station construction, less investment, short construction period and high power generation efficiency. However, the immature problem of biogas engines is still a bottleneck of technical application. The other four biomass power generation technology is basically mature.

However, as biomass power generation enterprises continue to enter the market and the scale is increasing, the layout of the biomass power generation industry appears obvious unreasonable, leading to the competition for biomass energy and the soaring price of biomass energy. For example, according to the total amount and density of energy in Jiangsu Province, the raw material collection radius of a power plant is not less than $50 \mathrm{~km}$. However, more than 10 existing projects have been intensively built in a radius of $200 \mathrm{~km}$ in northern Jiangsu. The initial stage of industrial development, the cost caused by its raw materials, as well as further lead to the lack of storage of biomass energy, which led to its power supply issues, need to be considered[4].

The increasing consumption of non-renewable fossil fuels, such as oil, and the pollution they cause have led to the development of alternative renewable green energy. Compared with traditional fossil fuels, biomass liquid fuel such as fuel ethanol and biodiesel has many advantages such as non-sulfur content and low nitrogen content. More importantly, carbon, the main element of biomass liquid fuel, participates in the carbon cycle in nature unlike the traditional fossil fuels, traditional fossil fuels are exploited to develop carbon elements in the stable geology. After being burned to produce heat, the traditional fossil fuels are discharged as carbon oxides into the natural world, equivalent to the existing natural resources Increase the total amount of carbon, and the production and consumption of carbon from biomass liquid fuel are completely taken from the carbon recycled in the existing natural world without increasing the total amount of carbon in the existing natural circulation. The biomass liquid fuel the energy generated is actually from solar energy. Therefore, biomass liquid fuel is a green energy that does not destroy the balance of natural carbon and the balance of thermal energy in nature.

\section{Analysis of the Market Structure of Agricultural Biomass Energy Industry in China}

The market structure refers to a concrete manifestation of the relationship among enterprises, between enterprises and enterprises or between enterprises and consumers. The market structure includes four basic forms: perfect competition, monopolistic competition, monopoly and oligarchy, with the degree of competition decreasing sequentially and the degree of monopoly gradually strengthened. With the strengthening of monopoly, there are more barriers to entry. Almost half of the production and management of rural biomass energy industry in our country is the mode of operation of peasants one by one; the other half comes from large and medium-sized biomass enterprises with large scale of production and operation. Due to the limited cost and resource distribution, most small and medium-sized biomass production enterprises of farmers and non-government-owned small and medium-sized biomass enterprises are relatively decentralized management modes, lack of effective organization, uneven product quality and lack of competitiveness in sales. The majority of large-scale biomass enterprises are state-controlled enterprises, which have higher product standardization and organization. Due to the large number of operators in the agricultural field, the market share is also relatively dispersed. About 740 million rural households in China are "segmented," and the development of rural biomass energy industries 
depends mainly on the distribution of raw materials, so there is almost no industry concentration. According to the classification of market structure to infer the concentration of rural biomass energy industry in our country, the concentration of rural biomass energy industry in our country is undoubtedly decentralized. There are two main reasons that cause the low concentration of rural biomass energy industry in our country. On the one hand, the raw materials required for industrial development are dispersed in a wide range of producers due to the space constraints of land operations and livestock breeding [5]. On the other hand, due to the restriction of land ownership in our country, land transfer is more difficult and the production of rural biomass energy is harder to form a horizontal joint.

Agricultural biomass products include particulate fuels, biogas, gas fuels, power generation, liquid fuels and the like. Product differences mainly depend on the differences in the types and quantities of local biomass raw materials. The main reasons for the differences in biomass raw materials are the geographical differences of raw materials, the natural conditions in the region and the economic level that affect the production of biomass raw materials. The biomass energy products The production of natural reproduction and social reproduction must be taken into account. Due to the seasonal characteristics of crops and agricultural products, the production of agricultural biomass is closely related to the local natural conditions and agricultural production conditions. To a certain extent, the biomass in different regions cannot control the difference between products. For large and medium-sized biomass enterprises, differences in collection time, transportation costs, storage costs and the like brought by the collection of raw materials by biomass energy production enterprises are also factors that cause product differentiation due to the different production distribution of farmers' biomass raw materials First, the application of biomass technology will also bring the product corresponding product differentiation.

\section{Chinese Agricultural Biomass Energy Industry Source Market Behavior Analysis}

As a high-tech enterprise, biomass energy companies can be divided into four phases according to the theory of enterprise life cycle: start-up, growth, maturity and recession [52]. In the whole process of biomass business growth, the risk always exists. Because the risk is the key factor that constrains the supplier's willingness to provide capital, the risks are not the same in different stages. Compared to hydropower companies, hydropower generation technology is relatively advanced and mature, the development level is relatively stable, the risk is small, a wider range of financing available, and other renewable energy enterprises, biomass enterprises are still in In the start-up period, financing is more difficult than in other stages. The startup enterprises are faced with the technical risks in the process of technological research and development. The market risks caused by the new products brought by technological innovation are not accepted by the market or can not obtain sufficient market share. The initial investment in technological innovation can not be recovered on schedule or Risk factors such as the financial risk of not being able to achieve a satisfactory rate of return are greater than those in the latter part of the period. As a result, the sources of financing for obtaining the narrowest and different sources of funding are different from those of their investment objectives and preferences. Because of its own characteristics, commercial banks pay attention to the principle of safety, liquidity and profitability in their investment principles, and ensure the safety of funds as the first principle. In the early stage of business, the assets owned by the enterprise were mainly intangible assets. There was neither physical assets available for collateralization nor suitable guarantee. In addition, the unpredictability of the benefits of biomass projects also affected the majority of commercial banks' active involvement in biomass enterprises the projects are all newly-established enterprises with less experience. Commercial banks lack the experience of long-term follow-up and analysis of such projects. In addition, such projects often show weak repayment ability and poor profit expectations in the early stages of construction. This makes commercial banks Have to be cautious so that commercial banks can not become the major funding providers for start-up biomass companies. On the other hand, bio-energy enterprises in the early stage of business often fail to gain the approval of the public due to the disadvantages of scale of operation and profitability. At this time, it is very difficult for enterprises 
to raise funds for development through the listing of the stock market.

Can be seen from the funding channels, the traditional bank credit funds, capital markets, etc. are not very willing to get involved in the start-up period of biomass energy enterprises, the available financing channels are limited. Because of the high-tech requirements, high-risk and high-input characteristics, bioenergy enterprises need a lot of financial capital support. In the initial stage, the main business objectives, technical level, scale, profitability of renewable energy enterprises and The degree of risk and so on make the enterprise's external financing ability is relatively weak. Funds from different sources also have different levels of difficulty in raising funds, stability costs and risks. The means of financing for the establishment of a biomass energy enterprise at the stage of its development should be adapted to its characteristics. Choosing the appropriate means of financing means financing can solve the problem of shortage of funds.

\section{Conclusions}

Biomass energy is the only renewable energy that can fix carbon. At present, the development of biomass energy in the world has become an important measure to adjust the energy structure, reduce greenhouse gas emissions and achieve sustainable development. Many varieties of biomass resources, large differences in characteristics, can be converted into electricity, hot water, gas and liquid fuels through different technologies. In addition to depending on the amount of resources, the degree of utilization of biomass energy resources is more important than the advanced nature of various conversion technologies. After more than 20 years of development, many technologies have been in the stage of pre-industrialization and industrial demonstration and have not yet achieved industrialization. The development prospect is good. In view of the development of various utilization technologies of biomass energy, recently, based on the biomass anaerobic digestion process Of the household biogas projects to deal with livestock manure and industrial organic wastewater large and medium-sized biogas projects, has begun to take the industrial scale, there will be greater development. Expected in the next 20 to 30 years, in addition to rural households with biogas and agricultural production, ecological environment combined with the development of a comprehensive utilization model, the more tended to develop biomass distributed energy systems, that is, to the independent decentralization of small biomass gasification Power generation, combined cycle power generation and cogeneration direction.

\section{References}

[1] Solow. R. M. A contribution to Theory of Economic Growth [J]. Quarterly Journal of Economic. 1956 (70):65-94.

[2] Baumol, W. J. Productivity Growth, Convergence and Welfare: What the Long-Run Data show [J]. American Economic Review, 1986, 76: 1072-1085.

[3] Ciccone A. Agglomeration Effects in Europe [J]. European Economic Review, 2002, 46(2):213- 227.

[4] Stel, A.J. Nieuwenhuijsen, H.R. Knowledge Spillovers and Economic Growth: An Analysis Using Data of Dutch Regions in the Period 1987-1995 [J]. Regio nal Studies, 2004, 38(4): 393-407.

[5] Fingleton, B. Spurious Spatial Regression: Some Monte Carlo Results with a Spatial Unit Root and Spatial Co-integration [J]. Journal of Regional Science, 1999, 39:1-19. 